\title{
LAND USE CHANGE PREDICTION IN DHAKA CITY USING GIS AIDED MARKOV CHAIN MODELING
}

\author{
Md. Shahidul Islam* Raquib Ahmed \\ Institute of Environmental Science, University of Rajshahi, Rajshahi 6205, Bangladesh \\ *Corresponding author (email: shahidul_rubd@yahoo.com)
}

\begin{abstract}
The main objective of this paper is to evaluate the land use change in Dhaka City based on the need and purpose to predict future scenario of Dhaka City. Dhaka being a mega city has been challenged by numerous difficulties like unplanned urbanization, traffic congestion, water logging etc. Land use classification and analysis is performed using a GIS and Remote sensing technique, and GIS aided 'Markov Cellular Automata' technique is used to model the land use change. Based on the past trend (from 1991 to 2008) of land use changes, the future land use map of Dhaka city for the year of 2020 and 2050 has been generated. And collected maps and images were sorted and classified for analysis and interpretation. Landsat TM image of 1991 and Google image of 2008 were employed in this study to produce land use classification based on Anderson modified version method. IDRISI, Land Change Modeler (LCM) was used to analyze the land use/cover changes between various classes during the period 1991-2008. It is assumed that this kind of research will contribute to shaping the urban form of the city in a planned manner. So, that Dhaka can be a much more livable and planned city in near future.
\end{abstract}

Key words: Land use, land use change, land use modeling.

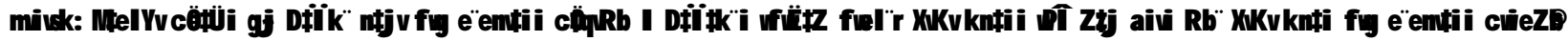

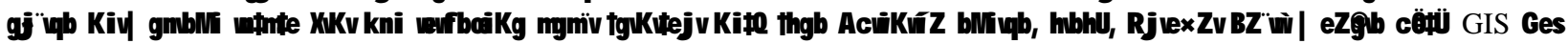

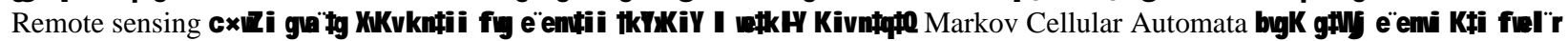

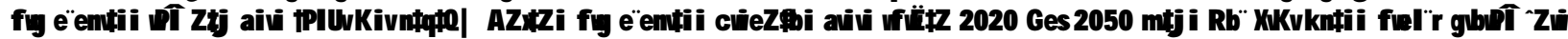

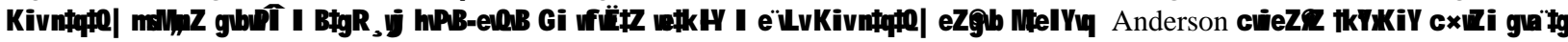

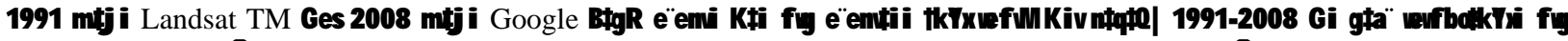
e"envi i c weZ

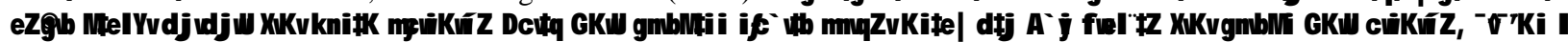
emeun th M" gn bM Mfi c w Y YZ nfe|

\section{Introduction}

Generally, land use change (LUC) is the modification of a piece of land. This change is based on the purposes of need, which is not necessarily only making the change in land cover but also change in intensity and management (Verburg et al. 2000). Land use/land cover changes are critical issue that degrade biodiversity and create impact on human life. The International Geosphere-Biosphere Program (IGBP) and the International Human Dimension Program (IHDP) initiated a joint international program to study the land use/land cover change (LULCC) considering the enormous impacts and implications generating from the changes of land use/land cover. They commended the necessity of improved understanding, modeling and projections of land dynamics from global to regional scale and focusing particularly on the spatial explicitness of processes and outcomes (Geoghegan et al. 2001).

EIU (2010) announced through a survey by the Economist Intelligence Unit (EIU), affiliated with the UK-based weekly that Dhaka is the second worst livable city in the world. Dhaka is now one of the world's fastest growing mega cities. In recent times, Dhaka has been challenging numerous difficulties like unplanned urbanization, extensive urban poverty, water-logging, growth of urban slums and squatters, traffic jam, environmental pollution and other socio-economic problems.

In this regard, it is much needed to track the land use changes over time and predict the future scenario of Dhaka city. In this article, analysis is performed by a remote sensing based land use prediction modeling method called 'Markov Cellular Automata'. Based on past trend (from 1991-2008) of land use changes, the future land use map of Dhaka city for the year of 2020 and 2050 has been generated. The result shows that urban built-up areas will increase significantly. The major contributions for this transformation to built-up areas will be from water bodies, cultivated land and vegetation land use types (Islam 2011). The decision makers as well the city planners can initiate appropriate plans based on the outcome of this research. This kind of analytic research can be remarkable in making Dhaka a much livable and planned city in near future. 


\section{Problem identification}

Bangladesh has been passing through a hasty process of urbanization and population growth since the last few decades. Rapid growth of population, unplanned urbanization and industrialization in the outer periphery of Dhaka city has created pressure on the changes in land use pattern. The area has been experiencing hasty changes in land use for infrastructure development in recent years. It is important to study the loss of cultivated land, vegetation, water bodies and wet/lowlands and also to see how and what changes occurred through. Most of the economic development activities are focused in and around Dhaka city. These changes have rapidly transformed Bangladesh from a subsistence agrarian economy into rapidly industrialized country. The growing urbanization in the outer periphery of Dhaka Metropolitan city has created extra pressure to change in the land use pattern (RAJUK 1997). Objective of this research therefore was to predict the future land use change in Dhaka City.

\section{Geographical location of the study area}

The study area, a part of Dhaka City and Savar area, is located in the central part of Bangladesh. Geographically, this area is in the southern part of Madhupur region. The study area lies between $23^{\circ} 44^{\prime} \mathrm{N}$ and $24^{0} 02^{\prime} \mathrm{N}$ latitudes and $90^{\circ} 12^{\prime} \mathrm{E}$ and $90^{\circ} 26^{\prime} \mathrm{E}$ longitudes and the total area about is $414.68 \mathrm{sq} \mathrm{km}$. The study area is included in the survey of Bangladesh Toposheet numbers $79 \frac{I}{1}, 79 \frac{I}{2}, 79 \frac{I}{5}$ and $79 \frac{I}{6}$. Based on flood control infrastructures, the study area is divided into two parts: Turag river east and Turag river west (Fig. 1).

Table 1. Land use/cover classification scheme in the study area.

\section{Methodology}

Collected maps and images were sorted and classified for analysis and interpretation. Classification was performed based on the Google Earth image 2008 utilizing observation points recorded during field visit. Landsat TM image of 1991 and Google image of 2008 were employed in this study to produce land use/cover categories of 1991 and 2008 respectively. Arc GIS and Erdas Imagine software were used to device land use/cover classification in a multi-temporal approach.

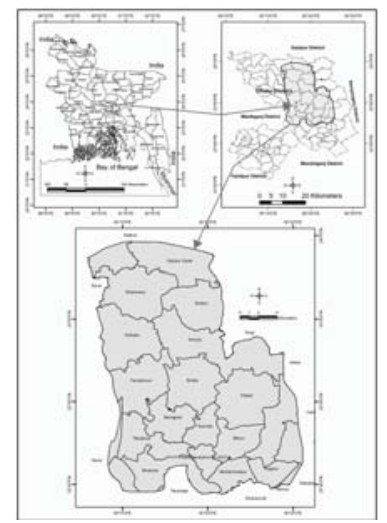

Fig. 1. Geographical location of the study area (Source: Prepared by the authors based on Banglapedia 2004).

A modified version of the Anderson Scheme Level I (Anderson et al. 1976) was adopted to study the land use/cover change. This system produced multilevel land use/cover type classification of which Level I classes can be mapped from Landsat data or from high altitude air photo/imaging. To predict the future land use of Dhaka city, remote sensing techniques have been used. Eight land use types have been identified for this research (Table 1).

\begin{tabular}{|l|l|}
\hline Land use/Land cover types & \multicolumn{1}{|c|}{ Description } \\
\hline Built-up & $\begin{array}{l}\text { Residential, commercial and services, industrial, socio-economic infrastructure and mixed } \\
\text { urban and other urban }\end{array}$ \\
\hline Bare soil/landfill & Exposed soils, landfill sites, and areas of active excavation. \\
\hline Cultivated land & Agricultural area, crop fields, fallow lands and vegetable lands. \\
\hline Vegetation & Deciduous forest, mixed forest lands, palms and others. \\
\hline Water-bodies & River, permanent open water, lakes, ponds and reservoirs. \\
\hline Wet/lowlands & Permanent and seasonal wetlands, low-lying areas, marshy land, rills and gully, swamps. \\
\hline $\begin{array}{l}\text { Transport and } \\
\text { communications }\end{array}$ & Transportation, roads and airport. \\
\hline Others & Brick fields and unidentified soil. \\
\hline
\end{tabular}

Source: Adopted from Anderson et al. (1976). 
The training sites developed for this research are based on the reference data and ancillary information collected from various sources as mentioned earlier. The supervised image classification method is applied. Eight separable land use/cover types have been identified in this study such as built-up, bare soil/landfill, cultivated land, vegetation, water bodies, wet/lowlands, transport and communication and others. These are shown in Table 1.

Land Change Modeler for ecological sustainability is integrated software developed by IDRISI Andes for analyzing land cover change by which maps were analyzed and found two land cover maps that have identical legends (same code for each class). The change analysis panel provides a rapid quantitative assessment of change by graphing gains and losses by land cover categories. A second option, net change, shows the result of taking the earlier land cover areas, adding the gains and then subtracting the losses. The third option is to examine the contributions to changes experienced by single land cover (IDRISI 2006). The Change analysis was performed between pairs of images of 1991 and 2008. Accordingly the transitions and exchanges that took place between the various classes during the years were obtained both in a map and graphical form. All the units were changed into hectares (ha). Transitions below 0.1 ha were ignored. Cross classification found its most common application in land cover change analysis where a cross tabulation or a cross correlation is done between two qualitative maps of two different dates that targets on the same features (IDRISI 2006). It is used to compare two classified images where the classification assigns the same unique and distinct identifier to each class on both the dates. The aim is to evaluate whether the areas fall into the same class on the two dates or a change to a new class has occurred. In Andes edition by running a CROSSTAB module we have got a new image based on all the unique combination of values from the two images in which each unique combination of input values has a unique output value and a cross tabulation table.

The cross tabulation matrix shows the distribution of image cells between the classes. The categories of date 1 are displayed on the $\mathrm{X}$-axis while in Y-axis displays the same categories of date 2. The cross tabulation shows the frequencies with which classes have remained in same (along with the diagonal), or have changed in different classes (off-diagonal frequencies). Cross correlation images show all possible combinations that are used to produce two types of change images. These relative frequencies are known as transition probabilities and are an underlying basis for Markov Chain prediction of future transitions.

\section{Results and Discussion}

Land use Change Analysis

From the classified image, the area of each land use class was computed (Table 2; Figs. 2 and 3) and compared statistically if there are differences between the images.

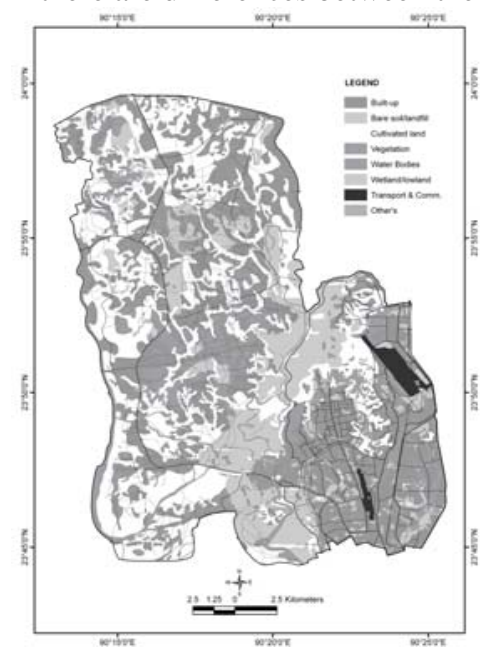

Fig. 2. Land use map in the study area, 1991

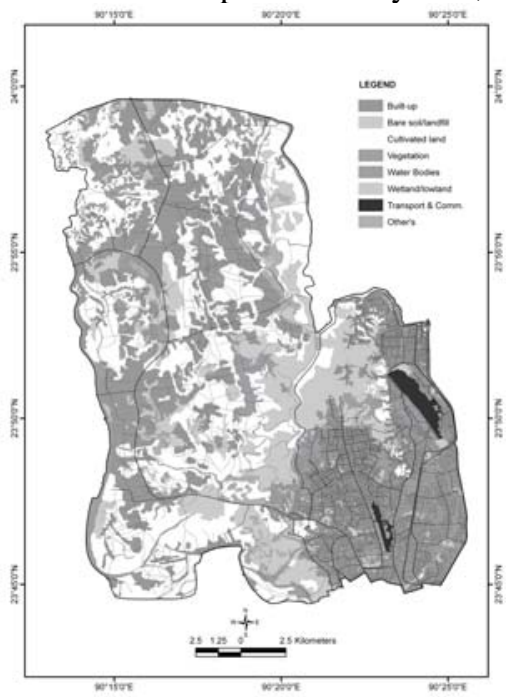

Fig. 3. Land use map in the study area, 2008 (Source: Figs 2 \& 3 prepared by the authors based on Landsat TM image, 1991 and Google image, 2008).

From Table 2, it is clear that over the years built-up area has increased distinctly. It is also noteworthy that there is an evident decrease in vegetation, water-bodies, cultivated land and wet/lowland. The transport and communication has increased rapidly and loss in bare soil/land filled is also found. It is now possible to predict the land use/cover change. 
Table 2. Summary of land use classification statistics between 1991 and 2008.

\begin{tabular}{|l|l|l|c|c|}
\hline Land use categories & 1991 area (ha) & 2008 area (ha) & 1991-2008 area changed (ha) & Changed area (\%) \\
\hline Built-up & $11866(28.61 \%)$ & $18451(44.49 \%)$ & 6585 & +55.49 \\
\hline Bare Soil/ landfill & $2420(5.84 \%)$ & $2090(5.04 \%)$ & -330 & -13.64 \\
\hline Cultivated land & $10395(25.07 \%)$ & $8050(19.41 \%)$ & -2345 & -22.56 \\
\hline Vegetation & $5418(13.06 \%)$ & $2589(6.24 \%)$ & -2829 & -52.21 \\
\hline Water-bodies & $3196(7.71 \%)$ & $2068(4.99 \%)$ & -1128 & -35.29 \\
\hline Wet/lowlands & $5829(14.06 \%)$ & $4732(11.41 \%)$ & -1097 & -18.82 \\
\hline Trans. and comm. & $2185(5.27 \%)$ & $2692(6.49 \%)$ & 507 & +23.20 \\
\hline Others & $159(0.38 \%)$ & $796(1.92 \%)$ & 637 & +400.63 \\
\hline
\end{tabular}

Source: Analysis from the land use map 1991 and 2008; + or - signs indicate direction of change.

Fig. 4 shows the changes in area (increasing or decreasing) for most of the classes. Agricultural, vegetation and wet/lowland have clearly decreasing trends while built-up, bare soil and transportation and communication have clearly indicated increasing trends. And the other classes show slight changes.

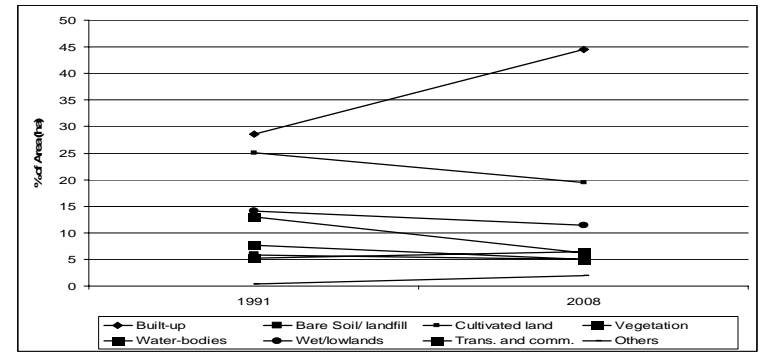

Fig. 4. Land use change trends within 1991-2008 (Source: Table 2).

\section{Change Detection using LCM}

Land Change Modeler (LCM) was used to analyze the land use/cover changes between various classes during the period 1991-2008 (Fig. 5). The basic principle used in the module is to evaluate the trend of the change from one land use category to other, the impact of influencing factors such as roads and different types of visible and invisible infrastructures, and finally predict (short and long term) the land use pattern based on the previous change trend. There are of course several modules already developed such as Markov Chain Analysis, Time Series Analysis, Geomod etc., but LCM is at the moment a widely used ecological modeling tool. This is still under experimental stage, but bears a lot of potentiality. The module works on Neural Network and needs to reach accuracy greater than $70 \%$, but accuracy depends much on influencing variables. Though research influencing variables were very limited and could not expect much accuracy, the level of accuracy obtained till now was satisfactorily relative. The land use change was assessed through evaluation of gains and losses by classes. Most of the classes have both gains and losses, with the exception to water bodies which show losses only. During the period from 1991-2008 agricultural land has been lost $78.31 \%$ and gained $63.72 \%$, with a net loss of $14.59 \%$. Vegetation has been lost $36.28 \%$ and gained $19.36 \%$ in $1991-2008$ with a net loss of $16.92 \%$. Wet/lowlands has been lost $23.57 \%$ and gained $24.85 \%$ in 1991-2008 with a net gain of $1.28 \%$. There was no gain in the area of water bodies during the periods 19912008 , but the area of water-bodies was lost $10.27 \%$ during the period 1991-2008. On the other hand, builtup area was lost about 56.42\% and gained $71.26 \%$ with a net gain of $14.84 \%$ during 1991 to 2008. And the same periods, bare soil/landfill was not changed and transport and communication was gained $8.36 \%$.

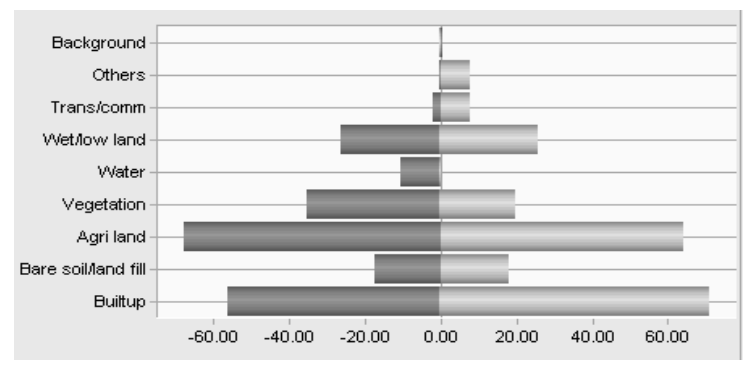

Fig. 5. Gains and losses of land use categories between 1991 and 2008.

Fig. 6 shows a pictorial representation of significant changes and summarizes the various land use/cover classes that has undergone transitions from one to another during the period from 1991 to 2008. Bare soil/landfill, agricultural land and vegetated area were converted into built-up area, built-up area converted into agricultural land and vegetated area, vegetation and wet/lowland area converted into agricultural land and a small part of agricultural land converted to wet/lowlands. For the classes of land use change analyzed above (built-up area and seasonal agricultural land) several reasons are responsible. First, the seasonal agricultural land is a 
rotating system, where lands were used for crop production and then left for the recovery for a certain period of time. During the recovery period, it remained as a bare soil and then passes to wetland or vegetation land as a natural succession. Second, most of the wetland and vegetated lands are still under a condition to facilitate the farming work before the cultivation or to renew green evaluation for livestock grazing. Third, some wetland areas with declined vegetated area or the vegetation cover of built-up area can be recovered and the class is changed to wetland. Fourth, forest is used to local residents as fuel and the empty places are used for agricultural and built-up purposes. Fifth, some changes represent an error in image classification, as there are difficulties to adequately separate the seasonal agricultural land, built-up area and wet/lowland in some areas depending on the conditions of the class and the season. Even though the images used in this study belong to the same season (dry) whereas some differences in vegetation phonology can be observed.

\section{CA Markov modeling}

In Markovian processes the future state of a system in time $t_{2}$ can be modeled based on the immediate preceding state; time $t_{1}$. A Markov chain is a random process where the following step depends on the current state. Markov produces a transition matrix (Table 3), a transition area matrix and a set of conditional probability images by analyzing two qualitative land use images (Fig. 7) from two different dates (1991 and 2008). In Table 3, the rows represent the older land use/cover classes and the columns represent the newer land use/cover categories. Here class 1 to class 8 chronologically represent built-up area, bare soil/landfill, cultivated land, vegetation, water-body, wet/lowlands, transport and communication and others land respectively. Markov analysis was performed for the multi-temporal land cover images of 1991-2008 including predicting year of 2020 as shown in Table 3.

Table 3. Markov prediction to 2020 based on land use maps of 1991 and 2008 (Given probability of changes to the values in bold shown below).

\begin{tabular}{|c|c|c|c|c|c|c|c|c|}
\hline Classes & BU & BL & AL & VG & WB & WL & TC & OT \\
\hline BU & $\mathbf{0 . 6 1 4 0}$ & 0.0265 & 0.1937 & 0.0880 & 0.0011 & 0.0385 & 0.0282 & 0.0098 \\
\hline BL & 0.5156 & $\mathbf{0 . 1 7 7 4}$ & 0.2031 & 0.0507 & 0.0005 & 0.0176 & 0.0351 & 0.0000 \\
\hline AL & 0.2624 & 0.0638 & $\mathbf{0 . 5 0 3 3}$ & 0.0510 & 0.0001 & 0.1085 & 0.0010 & 0.0098 \\
\hline VG & 0.3469 & 0.0532 & 0.3784 & $\mathbf{0 . 1 6 8 8}$ & 0.0000 & 0.0358 & 0.0165 & 0.0002 \\
\hline WB & 0.0776 & 0.0169 & 0.0850 & 0.0125 & $\mathbf{0 . 7 3 9 7}$ & 0.0382 & 0.0068 & 0.0155 \\
\hline WL & 0.0671 & 0.0776 & 0.2685 & 0.0002 & 0.0003 & $\mathbf{0 . 4 8 7 8}$ & 0.0044 & 0.0940 \\
\hline TC & 0.0350 & 0.0002 & 0.0084 & 0.0161 & 0.0005 & 0.0044 & $\mathbf{0 . 9 3 4 7}$ & 0.0001 \\
\hline OT & 0.0619 & 0.0000 & 0.0000 & 0.0000 & 0.0000 & 0.6676 & 0.0110 & $\mathbf{0 . 2 5 9 5}$ \\
\hline
\end{tabular}

Note: $\mathrm{BU}=$ Built-up, BL = Bare soil/landfill, AL = Agriculture land, VG = Vegetation, WB = Water bodies, WL = Wet/lowland, $\mathrm{TC}=$ Transport and communication, and OT $=$ Others.

According to this transition matrix shown in the Table 3, the probability of vegetation is only $17 \%$ for the period of 17 years. The probability of conversion from vegetation to agriculture and built-up areas are $38 \%$ and $35 \%$ respectively. Similarly the probability of wet/lowlands classes change into 27\% agricultural land and 7\% built-up area; agricultural land to change to built-up areas are $26 \%$ and wet/lowlands are $11 \%$; bare soil/landfill area change to built-up area 51\% and agricultural land 20\%. However, the areas that are likely to be invaded by classes of built-up area in 2020 are shown in Fig.7.

It can be seen from the figure given below that according to Markov transition probability the vegetation land are highly vulnerable to infestation by study area in the next 17 years. The probabilities of the invasive to encroach into the wet/lowlands are as high as $49 \%$ (Table 3 ). However, it can be noticed that those areas which were originally classified under transport and communication, and others area is not represented in the map and the value is shown as near about 0 .
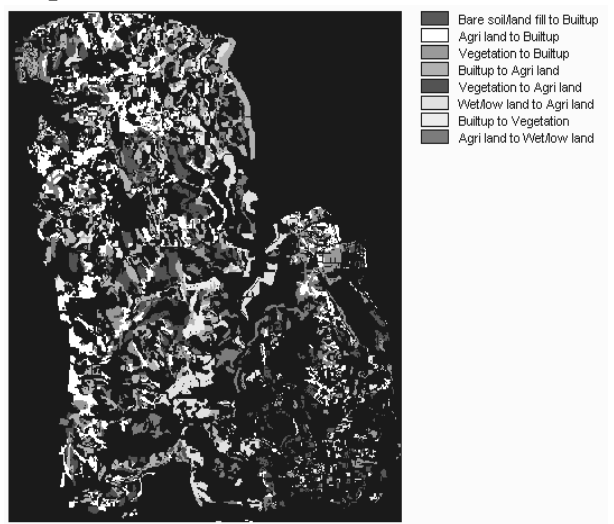

Fig. 6. Combined land use change map of 1991 and 2008. 


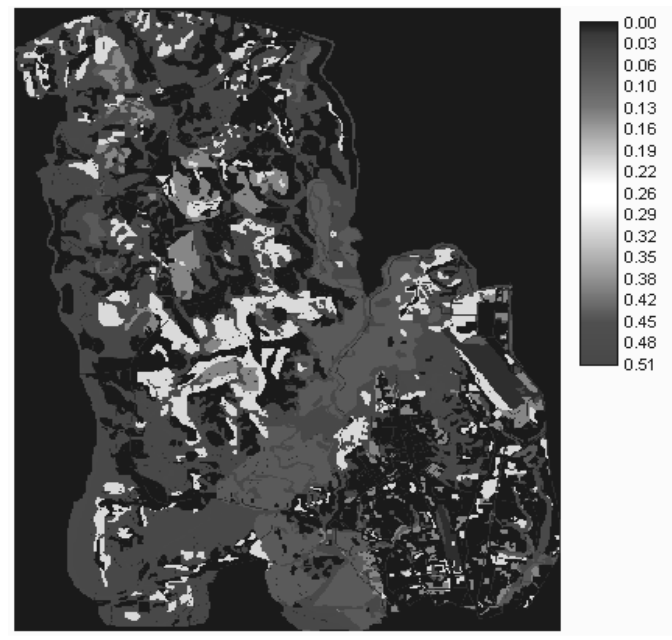

Fig. 7. Projected Markov conditional probability matrices for built-up area 2020.

The above map indicates that the probability of wet/lowlands to convert into agricultural land and builtup area is as high as $27 \%$ and $7 \%$ (Table 3 ) in the next
17 years. However, it should be noticed that according to the table the probability of wet/lowlands to remain as wet/lowlands is $100 \%$ but this is not represented by the image. As in the previous image, the areas originally represented by classes' wet/lowlands and others area is shown in black and has a probability of 0 .

\section{Transition Probability Matrix}

The transition probability matrix records the probability of each land use category to change into the other category. This matrix is produced by the multiplication of each column in the transition probability matrix be the number of cells of corresponding land use in the later image.

In the 8 X 8 matrix (Table 4) shown below, the rows represent the older land use categories and the column represents the newer categories. Although this matrix was used as a direct input for specification of the prior probabilities in maximum likelihood classification of the remotely sensed imagery, it was however used to predict land use of 2020 .

Table 4. Transitional probability matrix derived from the land use map of 1991 and 2008 (Given probability of changes to the values in bold shown below).

\begin{tabular}{|c|l|l|l|l|l|l|l|l|}
\hline Classes & BU & \multicolumn{1}{|c|}{ BL } & \multicolumn{1}{|c|}{ AL } & \multicolumn{1}{|c|}{ VG } & WB & WL & TC & OT \\
\hline BU & $\mathbf{0 . 6 1 4 0}$ & 0.0265 & 0.1937 & 0.0880 & 0.0011 & 0.0385 & 0.0282 & 0.0098 \\
\hline BL & 0.5156 & $\mathbf{0 . 1 7 7 4}$ & 0.2031 & 0.0507 & 0.0005 & 0.0176 & 0.0351 & 0.0000 \\
\hline AL & 0.2624 & 0.0638 & $\mathbf{0 . 5 0 3 3}$ & 0.0510 & 0.0001 & 0.1085 & 0.0010 & 0.0098 \\
\hline VG & 0.3469 & 0.0532 & 0.3784 & $\mathbf{0 . 1 6 8 8}$ & 0.0000 & 0.0358 & 0.0165 & 0.0002 \\
\hline WB & 0.0776 & 0.0169 & 0.0850 & 0.0125 & $\mathbf{0 . 7 3 9 7}$ & 0.0382 & 0.0068 & 0.0155 \\
\hline WL & 0.0671 & 0.0776 & 0.2685 & 0.0002 & 0.0003 & $\mathbf{0 . 4 8 7 8}$ & 0.0044 & 0.0940 \\
\hline TC & 0.0350 & 0.0002 & 0.0084 & 0.0161 & 0.0005 & 0.0044 & $\mathbf{0 . 9 3 4 7}$ & 0.0001 \\
\hline OT & 0.0619 & 0.0000 & 0.0000 & 0.0000 & 0.0000 & 0.6676 & 0.0110 & $\mathbf{0 . 2 5 9 5}$ \\
\hline
\end{tabular}

Note: $\mathrm{BU}=$ Built-up, BL = Bare soil/landfill, AL = Agriculture land, VG = Vegetation, WB = Water bodies, WL = Wet/lowland, $\mathrm{TC}=$ Transport and communication, and OT $=$ Others.

Row categories represent land use classes in 2008 whilst column categories represent classes of 2020. As seen from the Table 4, built-up area also has a probability as high as 0.6140 to remain as built-up area in 2020 which signifies stability. Bare soil/landfill during this period is the highest class with a 0.5156 probability of remaining built-up area in 2020 which shows instability. Agricultural land also has a probability as high as 0.5033 to remain as agricultural land in 2020 which signifies stability. This, therefore, shows an undesirable change with a probability of change which is much higher than stability. On the other hand, the 0.3784 and 0.3469 probability of change from vegetation to agriculture and built-up area shows that there might be a high level of instability in vegetation during this period. Water-body which is the highest class has a 0.7397 probability of remaining as water-body and a 0.0850 probability of changing to agricultural land during this period. Wet/lowlands are the highest class with a 0.2685 probability of changing to agricultural land in 2020. The land estimated for transport and communications also has a probability as high as 0.0350 which experiences a minimal change in 2020. And other land which is the last class has a 0.2595 probability of remaining as other land and a 0.6676 probability of conversion to wet/lowlands; which may not however be a true projection of this class except there is an occurrence of drought in the region. 
Table 5. Projected land use/cover for the study area 2020.

\begin{tabular}{|c|c|c|c|c|c|c|c|c|}
\hline Classes & BU & BL & AL & VG & WB & WL & TC & OT \\
\hline Area (ha) & 19201.67 & 2059.07 & 7463.36 & 1665.39 & 2038.93 & 5829.83 & 2638.91 & 785.94 \\
\hline$\%$ & 46 & 5 & 18 & 4 & 5 & 14 & 6 & 2 \\
\hline
\end{tabular}

Note: $\mathrm{BU}=$ Built-up, BL = Bare soil/landfill, AL = Agriculture land, VG = Vegetation, WB = Water bodies, WL = Wet/lowland, $\mathrm{TC}=$ Transport and communication, and $\mathrm{OT}=$ Others.

The Table 5 stated above shows the statistic of land use projection for 2020. Comparing the percentage representations of this table, there exist similarities in the observed distribution particularly in 2008. This may tend to suggest no change in the classes between 2008 and 2020, but a careful look at the area in hectares between these two tables shows a change, although it is small. Thus in Table 6, built-up area still maintains the highest position in the class whilst others land retains its least position. Agricultural land takes up the next position, followed by built-up land and finally, wet/lowlands. As seen in Figure 8, there is likely to be compactness in Dhaka city by 2020 which signifies a huge crowd.

Again in another transition probability matrix, $8 \times 8$ matrix table presented below, the rows represent the older land use categories and the columns represent the newer categories. Although this matrix can be used as a direct input for specification of the prior probabilities in maximum likelihood classification of the remotely sensed imagery, it was however used to predict land use of 2050.

Table 6. Transitional probability matrix derived from the land use map of 1991 and 2008 (Given probability of changes to the values in bold shown below).

\begin{tabular}{|c|c|c|c|c|c|c|c|c|}
\hline Classes & BU & BL & AL & VG & WB & WL & TC & OT \\
\hline BU & $\mathbf{0 . 4 0 5 6}$ & 0.0475 & 0.2862 & 0.0695 & 0.0019 & 0.1037 & 0.0663 & 0.0191 \\
\hline BL & 0.4144 & $\mathbf{0 . 0 4 8 4}$ & 0.2833 & 0.0703 & 0.0016 & 0.0911 & 0.0748 & 0.0159 \\
\hline AL & 0.3757 & 0.0549 & $\mathbf{0 . 3 1 4 2}$ & 0.0632 & 0.0010 & 0.1335 & 0.0326 & 0.0245 \\
\hline VG & 0.3940 & 0.0518 & 0.3071 & $\mathbf{0 . 0 6 8 1}$ & 0.0011 & 0.1087 & 0.0501 & 0.0189 \\
\hline WB & 0.2158 & 0.0352 & 0.1916 & 0.0355 & $\mathbf{0 . 3 5 1 8}$ & 0.0986 & 0.0282 & 0.0238 \\
\hline WL & 0.2869 & 0.0597 & 0.2975 & 0.0438 & 0.0009 & $\mathbf{0 . 2 3 3 7}$ & 0.0279 & 0.0495 \\
\hline TC & 0.0956 & 0.0074 & 0.0521 & 0.0261 & 0.0014 & 0.0185 & $\mathbf{0 . 7 9 4 7}$ & 0.0028 \\
\hline OT & 0.2078 & 0.0596 & 0.2716 & 0.0274 & 0.0006 & 0.3291 & 0.0293 & $\mathbf{0 . 0 7 4 5}$ \\
\hline
\end{tabular}

Note: $\mathrm{BU}=$ Built up, BL = Bare soil/landfill, $\mathrm{AL}=$ Agriculture land, VG = Vegetation, $\mathrm{WB}=\mathrm{Water}$ bodies, WL = Wet/lowland, $\mathrm{TC}=$ Transport \& communication, and OT $=$ Others.

Row categories represent land use classes in 2008 whilst column categories represent 2050 classes. As seen from the Table 6, built-up land also has a probability as high as 0.4056 probability of remaining as built-up land and a 0.2862 probability of changing agricultural land in 2020 which signifies instability. Bare soil/landfill during this period was the highest class with a 0.4144 probability of remaining built-up area in 2020 which is instability. Agricultural land also has a probability as high as 0.3142 probability of remaining as built-up land and a 0.3757 probability of changing built-up land in 2020 which signifies instability. On the other hand, the 0.3940 and 0.3071 probability of change from vegetation to built-up and agricultural land shows that there is likely to be a high level of instability in vegetation during this period. Water body has the highest probability $(0.3518)$ of remaining as water body and a 0.2158 probability of changing to built-up land during this period. Wet/lowlands area which is the highest class has a 0.2975 and 0.2869 probability of changing to agricultural land and built-up area respectively in this time. Transport and communications which is the highest class has a 0.7947 probability of remaining as Transport and communications during this period. And others land which is the last class has a 0.0745 probability of remaining as others land and a 0.2716 probability of changing to agriculture land; which may not however be a true projection of this class except there is an occurrence of drought in the region.

Table 7. Projected land use/cover for the study area, 2050.

\begin{tabular}{|c|c|c|c|c|c|c|c|c|}
\hline Classes & BU & BL & AL & VG & WB & WL & TC & OT \\
\hline Area (ha) & 20519.18 & 2066.04 & 5841.15 & 1548.77 & 2045.37 & 6153.76 & 2647.50 & 787.52 \\
\hline$\%$ & 49 & 5 & 14 & 4 & 5 & 15 & 6 & 2 \\
\hline
\end{tabular}

Note: $\mathrm{BU}=$ Built up, BL = Bare soil/landfill, AL = Agriculture land, VG = Vegetation, WB = Water bodies, WL = Wet/lowland, $\mathrm{TC}=$ Transport \& communication, and OT $=$ Others. 
This may tend to suggest no change in the classes between 2020 and 2050, but a careful look at the area in hectares between these two tables shows some change. Thus in Table 7, built-up land still maintains the highest position in the class whilst other land retains its lowest position. Wet/lowlands take up the next position, followed by transport and communication, bare soil and finally, agricultural land. As seen in Figure 9, there is likely to be compactness in Dhaka city by 2050 which signifies crowdedness.

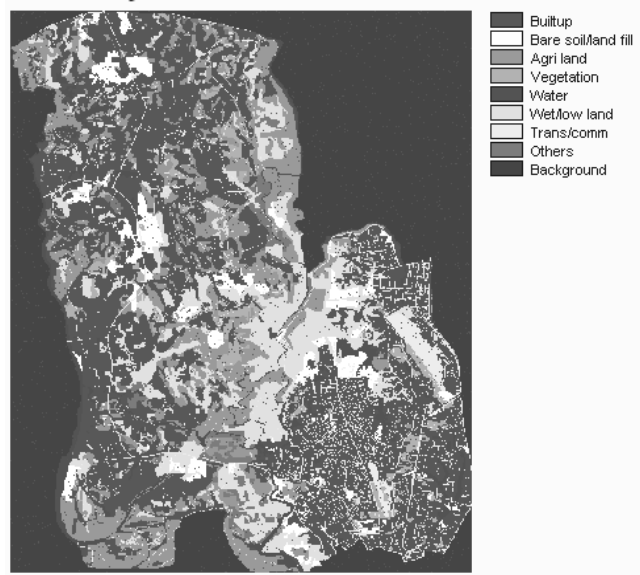

Fig. 8. Projected land use map for the study area, 2020.

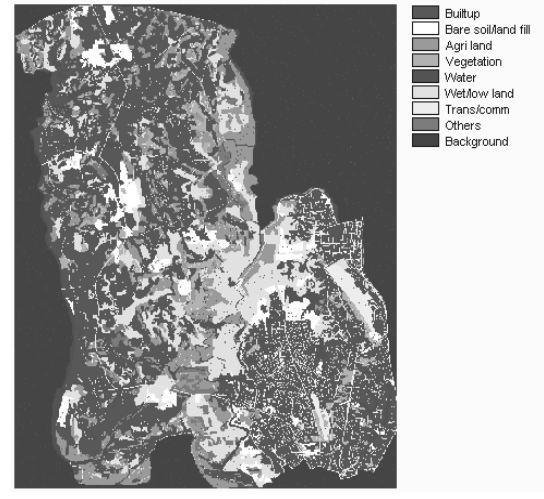

Fig. 9. Projected land use map for the study area, 2050.

Overall Matrix Land use Classification between 1991-2008 In IDRISI Andes software has been performed between land cover images of 1991-2008.

\section{CROSSTAB 1991-2008}

Similarly a CROSSTAB module was used for land cover images of 1991-2008.The cross tabulation result is shown in Table 8. For the classes of interest bare soil/landfill, agricultural land and vegetation are user accuracy of $59 \%, 49 \%$ and $61 \%$ was obtained respectively. As seen in the above Table 8 the lowest accuracy was recorded for agriculture land is $49 \%$.

Table 8. Cross tabulation of land use/cover 1991 (columns) against land use 2008 (rows).

\begin{tabular}{|c|c|c|c|c|c|c|c|c|c|c|c|c|}
\hline \multicolumn{13}{|c|}{1991} \\
\hline \multirow{10}{*}{2008} & Classes & $\mathrm{BU}$ & BL & $\mathrm{AL}$ & VG & WB & WL & TC & OT & Total & $\begin{array}{l}\text { Error of } \\
\text { Omission }\end{array}$ & $\begin{array}{c}\text { Users } \\
\text { accuracy }\end{array}$ \\
\hline & BU & 221420 & 0 & 0 & 0 & 0 & 0 & 0 & 0 & 221420 & 0 & 100 \\
\hline & BL & 13359 & 18878 & 0 & 0 & 0 & 0 & 0 & 0 & 32237 & 41 & 59 \\
\hline & AL & 69758 & 0 & 91112 & 0 & 0 & 24787 & 0 & 0 & 185657 & 51 & 49 \\
\hline & VG & 15717 & 0 & 0 & 24175 & 0 & 0 & 0 & 0 & 39892 & 39 & 61 \\
\hline & WB & 0 & 0 & 0 & 0 & 31880 & 0 & 0 & 0 & 31880 & 0 & 100 \\
\hline & WL & 0 & 0 & 0 & 0 & 0 & 70793 & 0 & 0 & 70793 & 0 & 100 \\
\hline & TC & 0 & 0 & 0 & 0 & 0 & 0 & 41298 & 0 & 41298 & 0 & 100 \\
\hline & OT & 0 & 0 & 0 & 0 & 0 & 0 & 0 & 12285 & 12285 & 0 & 100 \\
\hline & Total & 320254 & 18878 & 91112 & 24175 & 31880 & 95580 & 41298 & 12285 & 635462 & & \\
\hline \multicolumn{2}{|c|}{ Error of Omission } & 31 & 0 & 0 & 0 & 0 & 26 & 0 & 0 & & & \\
\hline \multicolumn{2}{|c|}{ Producers accuracy } & 69 & 100 & 100 & 100 & 100 & 74 & 100 & 100 & & & \\
\hline \multicolumn{2}{|c|}{ Overall accuracy } & \multicolumn{11}{|c|}{$57.30 \%$} \\
\hline
\end{tabular}

Note: $\mathrm{BU}=$ Built up, BL = Bare soil/landfill, AL = Agriculture land, VG = Vegetation, WB = Water bodies, WL = Wet/lowland, $\mathrm{TC}=$ Transport $\&$ communication, and $\mathrm{OT}=$ Others .

\section{Accuracy Assessment}

There are always ambiguities in acceptability of the result, particularly when the result predicts future based on unsettled variables. But however, there are again always some scopes of checking the result in GIS techniques. The location accuracy of land use change model of Landsat TM image of 1991 and Google Earth image 2008 was done using the clear and visible roads which were collected during the field work. In the case of classifying bare soil/landfill, cultivated/agricultural land and vegetation, and the user accuracy were $59 \%$, $49 \%$ and $61 \%$ respectively. The prediction of land use 
change was done on Neural Network built-in module in the Andes version of IDRISI. Iterations considered were 5000- sufficient for running the data. As seen in Table 8 the lowest accuracy was obtained as 57.30 for all the conversion types (Fig. 10).

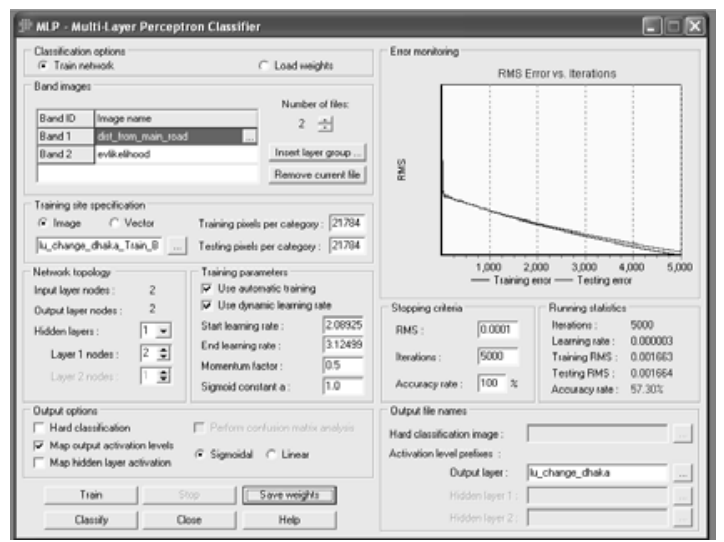

Fig. 10. Accuracy assessment of multi-layer perception classifier.

The system ran several times to give sufficient training (learning) to the system. The accuracy is not standard as per regular system as it is significantly lower than $70 \%$. But as mentioned earlier, in absence of sufficient number of authentic influencing variables the present accuracy was obtained, and hence it may be considered acceptable to some extent.

\section{Conclusion}

Dhaka is one of the fastest growing cities in the world. Many parts of this city are unplanned. This kind of research will contribute shaping the urban form of the city in a planned manner. The decision makers as well the city planners can initiate appropriate plans based on the outcome of this research. This kind of analytic research can be remarkable in making Dhaka a much more livable and planned city in near future.

\section{References}

Anderson JR, Hardy EE, Roach JT and Witmer RE. 1976. A Land Use and Land Cover Classification System for Use with Remote Sensor Data, U.S. Geological Survey, Professional Paper 964, p. 28, Reston, VA. (http://www.fws.gov/wetlands/_documents/gSandT/ OtherInformation/LandUseLandCoverClassification System.pdf)

Banglapedia 2004. Asiatic Society of Bangladesh, Dhaka.

EIU (Economist Intelligence Unit) 2010. The Economist, UK-based weekly magazine, February 14, 26 Red Lion Square, London WC1R 4HQ, United Kingdom. (https://www.economistsubscriptions.com/ecom529/global/)

Geoghegan J, Klepeis SCP, Mendoza PM, Yelena OR, Chowdhury R, Turner II BL and Vance C. 2001. Modeling tropical deforestation in the southern Yucatan peninsular region: comparing survey and satellite data. Agriculture, Ecosystems and Environment, 85: 25-46.

IDRISI 2006. Idrisi Andes Guide to GIS and Image Processing. Clark labs, Clark University, USA (http://www.cartografia.cl/download/manuales/idrisi_a ndes.pdf).

Islam MS. 2011. Land use Change and Environmental Degradation in Dhaka City Unpub. PhD Thesis, Institute of Environmental Science, University of Rajshahi, Bangladesh. 289 pp.

RAJUK 1997. Dhaka Metropolitan Development Plan (19952015) Rajdhani Unnayan Kartripakha, Dhaka. Vol. 1 \& 2.

Verburg PH, Chen Y, Soepboer W and Veldkamp A. 2000. GIS-based modeling of human-environment interactions for natural resource management. Applications in Asia. Proc. 4th Int. Conf. Integrat. GIS Environ. Modeling (GIS/EM4): Problems, Prospects and Research Needs, Banff, Alberta, Canada, Sept. 2 8, 2000, pp. 1-18. (http://gissrv.iend.wau.nl/ clue/banf/ banf71/banf71html).

Manuscript received on 10 June 2011 and revised on 7 January 2012 